\title{
Aortic Arch Syndrome
}

National Cancer Institute

\section{Source}

National Cancer Institute. Aortic Arch Syndrome. NCI Thesaurus. Code C34391.

A syndrome resulting from structural defects of the arteries that arise from the aortic

arch. Signs and symptoms include weakness, dizziness, arm numbness, blurred vision and transient ischemic attacks. 